\title{
O Processo de Construção e Reconstrução das Identidades dos Indivíduos nas Organizações
}

\author{
Karina Ribeiro Fernandes \\ José Carlos Zanelli
}

\section{Resumo}

As identidades dos indivíduos nas organizações são construídas a partir da interação humana, ao se compartilhar objetivos, regras e valores, entre outros, exercendo uma influência considerável sobre a motivação dos trabalhadores, assim como sua satisfação e produtividade. Este artigo pretende identificar, analisar e comentar o processo de construção das identidades dos indivíduos nas organizações. Pretende-se ainda verificar como ocorre o processo de reconstrução dessas identidades em ambientes de mudanças constantes. Será utilizado um enfoque teórico e interpretativo, argumentando que as organizações tendem a determinar o modo como os indivíduos percebem o conjunto de relações sociais relevantes para eles.

Palavras-chave: identidade; valores organizacionais; cultura organizacional; mudança organizacional.

\begin{abstract}
The identities of the individuals in the organizations are constructed from the interaction human being, to if sharing objectives, rules, values, among others, exerting a considerable influence on the motivation of the workers, as well as its satisfaction and productivity. This article intends to analyze and to comment the process of construction of the identities of the individuals in the organizations. It is still intended, to verify as the process of reconstruction of these identities occurs, in environments of constant changes. A theoretical and interpretative approach will be used, arguing that the organizations tend to determine the way as the individuals perceive the set of excellent social relations for them.
\end{abstract}

Key words: identity; organizational values; organizational culture; organizational change. 


\section{INTRODUÇÃO}

Assistimos hoje a transformações importantes no ambiente de trabalho. Cada vez mais os funcionários são convidados a vestir a camisa da empresa. Para isso devem estar conscientes e engajados com os valores organizacionais, bem como ter claramente definidos os objetivos que a organização pretende atingir e os meios para alcançá-los. É muito comum se afirmar que a principal responsabilidade dos gerentes é a de motivar seu pessoal; para isso é feito um trabalho de conscientização, que se inicia no momento de inserção do empregado no ambiente organizacional.

Conforme citado por Zanelli (2003), do ponto de vista social, a ordem que se estabelece, ou não, resulta do compartilhamento que ocorre na interação humana. Do ponto de vista individual, a identidade é elemento chave da realidade subjetiva e se encontra em relação dialética com a sociedade. Nesta acepção, o indivíduo é produto e produtor do sistema social.

Ao apresentar aos funcionários os ritos, crenças, valores, rituais, normas, rotinas e tabus da organização, o que se pretende é buscar a sua identificação com os padrões a serem seguidos na empresa. Dessa forma, se fornece um senso de direção para todas as pessoas que compartilham desse meio. As definições do que é desejável e indesejável são introjetadas pelos indivíduos atuantes no sistema, orientando suas ações nas diversas interações que executam no cotidiano.

Reconhecer os significados e a própria razão de ser da empresa, bem como se familiarizar com as percepções e comportamentos mais aceitos e valorizados na organização, conduz os funcionários a uma uniformidade de atitudes, o que é positivo no sentido de possibilitar maior coesão. No entanto pode levar a uma perda de individualidade, pois o comportamento dos indivíduos passa a ser uma extensão do grupo, muitas vezes se estendendo para ambientes externos da organização, quando passam a adotar comportamentos padronizados nas mais diversas situações.

O presente artigo pretende contribuir para o debate acerca desse processo de construção das identidades dos indivíduos nas organizações, argumentando que a padronização de atitudes pode ser prejudicial às pessoas e à própria organização, que perde em criatividade e falta de questionamentos, além de aumentar a resistência às mudanças, uma vez que as pessoas se sentem mais confortáveis agindo da forma a que estão habituadas e que aprenderam ser a maneira correta de agir. 


\section{Como São Formadas as Identidades dos Indivíduos nas Organizações}

Ao ingressar em uma organização, indivíduos com características diversas se unem para atuar dentro de um mesmo sistema sociocultural na busca de objetivos determinados. Essa união provoca um compartilhamento de crenças, valores, hábitos, entre outros, que irão orientar suas ações dentro de um contexto preexistente, definindo assim as suas identidades.

Segundo Dupuis (1996), são os indivíduos que, por meio de suas ações, contribuem para a construção de sua sociedade. Entretanto os indivíduos agem sempre dentro de contextos que lhes são preexistentes e orientam o sentido de suas ações. A construção do mundo social é assim mais a reprodução e a transformação do mundo existente do que sua reconstrução total. Para Berger e Luckmann (1983) a vida cotidiana se apresenta para os homens como realidade ordenada. Os fenômenos estão pré-arranjados em padrões que parecem ser independentes da apreensão que cada pessoa faz deles, individualmente.

Dentro dessa perspectiva, a ação humana, em nível do indivíduo e do grupo, mediada pelos processos cognitivos, e interdependente do contexto, varia conforme a inserção ambiental e o tipo de organização, tanto quanto também varia internamente em suas subunidades. É importante salientar que o universo simbólico integra um conjunto de significados, atribuindo-lhes consistência, justificativa e legitimidade. Em outras palavras, o universo simbólico possibilita aos membros integrantes de um grupo uma forma consensual de apreender a realidade, integrando os significados e viabilizando a comunicação.

Em outras palavras, a realidade é constituída por uma série de objetivos que foram designados como objetos antes da minha aparição em cena. O indivíduo percebe, assim, que existe correspondência entre os significados por ele atribuídos ao objeto e os significados atribuídos pelos outros, isto é, existe o compartilhar de um senso comum sobre a realidade.

É por meio desse compartilhar da realidade que as identidades dos indivíduos nas organizações são construídas, ao se comunicar aos membros, de forma tangível, um conjunto de normas, valores e concepções que são tidas como certas no contexto organizacional. Ao definir a identidade social dos indivíduos, o que se pretende é garantir a produtividade, pela harmonia e manutenção do que foi aprendido na convivência. É importante ressaltar que muitas vezes essas identidades precisam ser reconstruídas, quando a empresa se vê diante de situações que exigem mudanças. 


\section{O Papel da Cultura Organizacional no Processo de Formação DA Identidade dos Indivíduos nas Organizaçōes}

O fenômeno cultura organizacional já era estudado desde o início do século passado, a partir da experiência de Hawthorne, desenvolvida entre 1927 e 1932. Sob coordenação de Elton Mayo, adquiriu maior evidência, com a constatação da grande influência do grupo sobre o comportamento do indivíduo. Atualmente é dada grande importância ao estudo da cultura organizacional, por considerar que ela é determinante do desempenho individual, da satisfação no trabalho e da produtividade da empresa.

Considerando a afirmação de Motta e Vasconcelos (2002, p. 302), segundo os quais "para desenvolver-se e sobreviver, o grupo organizacional tem dois grandes problemas a solucionar: adaptar-se ao ambiente e manter a coerência interna", partiremos do conceito de que cultura organizacional é

o conjunto de pressupostos básicos que um grupo inventou, descobriu ou desenvolveu ao aprender como lidar com os problemas de adaptação externa e integração interna, e que funcionaram bem o suficiente para serem transmitidos aos novos membros como a forma correta de perceber, pensar e sentir, em relação a esses problemas (Schein, 1989, p. 12).

Podemos afirmar que é através da experiência coletiva que os membros da organização encontram respostas para as questões do cotidiano da empresa, pois são os valores e crenças compartilhados que definem seu modo de pensar e agir. Assim, ao definir padrões de comportamento com o objetivo de conservar a estabilidade e o equilíbrio do grupo, justifica-se a importância crescente atribuída à cultura organizacional.

Um importante aspecto para a sobrevivência de um indivíduo é a necessidade de construção de uma identidade, uma noção de totalidade que o leve a fazer convergir em uma imagem de si mesmo as muitas facetas do seu modo de ser, os muitos papéis que ele representa em diferentes momentos da sua experiência social. Assim, sucessivamente, o indivíduo vai-se diferenciando e se igualando conforme os vários grupos sociais de que faz parte, tornando-se uma unidade contraditória, múltipla e mutável.

Conforme citado por Silva e Vergara (2000, p. 5), "não há sentido em falar-se em uma única identidade dos indivíduos, mas sim em múltiplas identidades que constroem-se dinamicamente, ao longo do tempo e nos diferentes contextos ou espaços situacionais dos quais esses indivíduos participam". Sem compartilhar uma cultura comum, não poderíamos falar em construção de identidade, seja no 
nível dos indivíduos, dos grupos, ou da organização como um todo. A cultura organizacional pode ser vista, portanto, como o alicerce para a formação da identidade dos indivíduos nas organizações, não havendo como pensar a noção de identidade, se não for em função da interação com outros.

Assim, as identidades dos indivíduos são construídas de acordo com o ambiente em que se inserem envolvendo, entre outras coisas, as estruturas sociais, a cultura e o histórico das relações. Segundo Zanelli (2003), a organização, como sistema social, inserida em seu contexto, busca preservar sua identidade e sobrevivência. Para tanto, desenvolve uma estrutura normativa (valores, normas e expectativas de papéis, padrões esperados de comportamento e interação) e uma estrutura de ação (padrões reais de interação e comportamento), originada sobretudo nas posições dirigentes.

Vários outros autores corroboram essa afirmação, ao sugerir que deve haver preocupação dos dirigentes em desenvolver valores e padrões em comum, a fim de que os membros da organização possam trabalhar em conjunto e comunicarse, integrando as estratégias e objetivos gerais da organização, possuindo, assim, uma visão global do sistema.

Freitas (1991) entende que, de modo geral, as respostas que geram resultados favoráveis em determinada cultura são internalizadas como verdades inquestionáveis. Entre essas verdades ou pressupostos, encontram-se os diferentes elementos que formam a cultura organizacional: os valores, as crenças, os ritos, rituais e cerimônias, os mitos e histórias, os tabus, os heróis, as normas e o processo de comunicação. Cada um deles tem função específica na construção da cultura; mas todos servem para estimular a adoção, por parte dos empregados, do conteúdo difundido, além de reforçar uma imagem positiva da organização.

No entanto, a partir do momento em que as pessoas internalizam verdades inquestionáveis, passando a adotar comportamentos padronizados, colocam-se em posição de passividade, perdendo a percepção individual da realidade. Essa falta de questionamentos, vista como positiva no sentido de promover uma homogeneização de atitudes, pode ser muito negativa principalmente em ambientes de mudanças constantes, que primam pela criatividade e inovação. Quando um questionamento é visto como ameaça para a organização e possível desestruturação dela, a tendência é que o grupo se torne alienado; assim, a participação dos membros será praticamente nula.

A revisão da literatura nos leva a concordar em que o sucesso organizacional deve ser definido em termos concretos para os funcionários por meio dos elementos que compõem a cultura. Porém a maneira como os objetivos e metas serão atingidos podem ser flexíveis, a partir de um maior envolvimentos dos 
dirigentes no sentido de estimular a participação dos membros, levando a uma maior interação e conhecimentos mútuos.

Segundo Schein (2001) a cultura de uma organização pode ser aprendida em vários níveis, são eles: o nível dos artefatos visíveis, que compreende os padrões de comportamento visíveis, ou seja, a forma como as pessoas se vestem, se comunicam, entre outros; o nível dos valores que governam o comportamento das pessoas, que são mais difíceis de serem identificados, pois compreendem os valores que levam as pessoas a agirem de determinada forma; e por último o nível dos pressupostos inconscientes, que são aqueles pressupostos que determinam como os membros de um grupo percebem, pensam e sentem.

É importante diferenciar aqueles valores organizacionais que justificam a razão de ser da organização, e por isso se situam em um nível mais profundo, e outros referentes à maneira de resolver problemas do cotidiano da empresa. Os primeiros servem de guia, devendo realmente ser internalizados pelos membros que compõem a organização. Já os outros podem e devem estar abertos a sugestões, flexibilizando-se para se adaptar às exigências internas e externas do ambiente.

\section{Identidade Pessoal e Identidade Social}

Os conceitos de identidade pessoal e identidade social são distintos. Segundo Ting-Toomey (1998), a identidade pessoal refere-se ao modo como o indivíduo define suas características próprias, seu autoconceito, geralmente comparandose com outros indivíduos. Já a identidade social refere-se aos conceitos que o indivíduo desenvolve de si mesmo e que derivam de sua afiliação em categorias ou grupos, emocionalmente significantes para ele. Esse tipo de classificação inclui, entre outras, as identidades por afiliação étnica ou cultural, de gênero, de orientação sexual, de classes sociais, de idade ou profissionais.

Turner (1982) define a identificação social como o processo de alguém se localizar ou localizar outra pessoa dentro de um sistema de categorizações sociais; mas define simultaneamente a identidade social como a soma total das identificações sociais usadas por uma pessoa para definir a si própria. Assim, a maneira pela qual alguém é definido por outros influencia sua auto-identidade em algum grau.

Estudos realizados por Ashforth e Mael (1989) identificam três consequiências gerais da identificação do grupo, que são especialmente relevantes para o comportamento organizacional. Segundo eles, os indivíduos tendem a escolher 
atividades e instituições que sejam congruentes com suas identificações mais evidentes; a identificação afeta os resultados, como a coesão e a interação intragrupais; e a identificação reforça a fixação ao grupo e a seus valores, e aumenta a competição com grupos externos.

Podemos afirmar, portanto, que quanto maior a identificação dos indivíduos com a organização, maior o comprometimento desses. Os mesmos autores sugerem que a existência da diversidade na identificação do grupo pode levar a alguma dificuldade nas relações entre pessoas de identidades de grupos diferentes. Segundo Ting-Toomey (1998), os indivíduos tendem a experimentar maior grau de vulnerabilidade em seus encontros iniciais com pessoas de outros grupos do que com as pessoas do seu próprio grupo.

Lopes (2001) define o significado de identidade social como sendo construído pela ação conjunta de participantes discursivos, em práticas discursivas situadas na história, na cultura e na instituição. O mesmo autor cita algumas características importantes das identidades sociais, como se explicitam nos três itens abaixo.

- A sua natureza fragmentada, no sentido de que as pessoas não possuem uma identidade social homogênea, como se pudessem ser definidas por sexualidade ou raça, por exemplo.

- A possibilidade de que identidades contraditórias coexistam na mesma pessoa. Um exemplo seria pensar na existência de um homem que vote em um partido conservador, embora seja sindicalista.

. O fato de as identidades sociais não serem fixas, uma vez que estão sempre construindo-se e reconstruindo-se no processo social de construção do significado.

Em oposição a uma visão tradicional, que compreende a identidade social de um indivíduo como fixa e contínua, como algo que lhe pertence de modo quase permanente, uma corrente significativa de autores tem procurado desenvolver um conceito de identidade como algo fluido, multidimensional, dependente do contexto sociocultural das situações nas quais os indivíduos se vêem envolvidos, e como algo que possui forte componente relacional.

Sendo a identidade social construída a partir do momento em que os indivíduos se vêem como parte de um grupo, as organizações de trabalho representam um grupo muito expressivo na definição da identidade social dos seus membros. Daí a necessidade de se estudar a interação deles, uma vez que o convívio entre as pessoas pertencentes a esse grupo é intenso e significativo. 


\section{O Conceito de Identidade Organizacional}

As perspectivas intergrupais têm sido uma das principais estruturas para o entendimento das interações humanas, envolvendo indivíduos percebendo a si mesmos como membros de uma categoria social, ou sendo percebidos por outros como pertencentes a uma categoria social (Taylor \& Moghaddam, 1987).

Conforme Oliveira e Bastos (2001), seguindo o senso comum nos vemos como a mesma pessoa em diferentes interações. No entanto é possível também perceber que nos posicionamos de modos diferentes, em diferentes momentos e lugares, de acordo com os diferentes papéis que estamos exercendo.

Silva e Vergara (2000) concluem que, sendo a identidade algo que se constrói como produto das interações dos diferentes indivíduos e grupos, criando, portanto, um senso comum, tem sentido falar da existência de uma identidade organizacional.

Alguns autores vêem a identidade organizacional como algo que tende a ser preservado ao longo do tempo; outros argumentam que ela possui uma natureza fluida, contínua, adaptativa, ou seja, depende do modo como os membros organizacionais interpretam os valores e as crenças essenciais da organização nos diferentes contextos em que eles se deparam em sua trajetória.

O fato de os indivíduos terem identidades múltiplas e não uma identidade única contribui para a complexidade da identidade nas organizações. As maneiras como as identidades interagem ou se tornam destacáveis são importantes para um contexto organizacional. Assim, o estudo da identidade de uma organização envolve, necessariamente, a atenção com sua interação com várias identidades.

Gioia, Schultz e Corley (2000) ressaltam que a noção de identidade organizacional tem sido definida como sendo a compreensão coletiva dos membros da organização, sobre as características presumidas como centrais e relativamente permanentes, e que a distingue das demais, possuindo, assim, estreita relação com a imagem organizacional.

Devemos considerar que a cultura preserva a identidade organizacional, e essa se traduz na forma como os públicos da organização a vêem, a imagem que eles constroem a respeito dela. Assim, em uma cultura organizacional que busca interagir com o ambiente, adaptando-se a ele, essa personalidade que a organização assume tende a ser proativa, atenta às necessidades de mudanças, que se tornam cada vez mais presentes no ambiente organizacional. Dessa forma, a identidade organizacional é muitas vezes reconstruída para se adequar ao mercado. 
Na sociedade moderna, talvez as organizações sejam a arena mais significativa em que as identidades dos indivíduos são constituídas. Para muitas pessoas, sua identidade profissional ou organizacional pode ser mais persuasiva e importante do que as identidades atribuídas com base em gênero, idade, etnia, raça ou nacionalidade (Hogg \& Terry, 2000).

É fácil perceber que a experiência no mundo do trabalho é importante componente de aspectos identitários, pois nos leva a incorporar características, hábitos e valores compartilhados por um grupo com o qual passamos a maior parte do nosso tempo. Assim, o trabalho nos modifica, nos torna iguais em alguns aspectos, e nos separa e distingue em outros.

\section{Como São Orientadas as Identidades dos Indivíduos}

Devemos fazer distinções entre as identidades baseadas em categorias sociais como raça, gênero, etnia e classe, e as identidades baseadas em categorias como função organizacional ou tempo de serviço, pois estas últimas podem ser assumidas, difundidas ou perdidas quando o indivíduo deixa a organização.

Brickson (2000) identifica três modos distintos de como os indivíduos orientam as suas identidades nos diferentes contextos específicos em que se vêem envolvidos. Segundo o autor, essas orientações da identidade do indivíduo são ativadas em função da forma como esse indivíduo define a si mesmo, prioritariamente, em cada contexto, se como um indivíduo, como um ser interpessoal ou como um membro de um grupo.

Segundo este autor, quando a pessoa se define prioritariamente como indivíduo, tende a ativar uma orientação para a identidade pessoal, a ser motivada pelo auto-interesse, a conceber-se em termos de suas características e traços individuais e a avaliar-se por meio da comparação com os outros indivíduos.

Já quando se define prioritariamente como ser em relação com outros, a pessoa tende a ativar a orientação para uma identidade relacional, em que a principal motivação passa a ser a procura pelo benefício do outro. A concepção de si mesmo baseia-se, predominantemente, em seus papéis na relação com esses outros que significam algo para ela, e a auto-avaliação tende a dar-se em termos da proficiência com que ela desempenha seus papéis interpessoais diante desse outro.

Finalmente, ao definir-se prioritariamente como membro de grupo, a pessoa tende a ativar uma identidade de orientação coletiva. Sua motivação passa a ser a garantia do bem-estar de seu grupo, freqüentemente com relação a outros 
grupos. Ela procura caracterizar-se em termos do perfil ou do protótipo do grupo e tende a determinar seu autovalor com base na comparação de seu grupo com outros grupos.

Faremos aqui uma análise, posteriormente aprofundada, com relação às conseqüências da identificação descrita acima. Identificar-se prioritariamente como membro de um grupo é o que grande parte das organizações busca nos seus funcionários. A maioria das empresas procura motivar seus empregados nesse sentido. No entanto, se observarmos um indivíduo que se define prioritariamente como membro de um grupo, veremos que ele tenderá a perder completamente a sua identidade, e não mais conseguirá reconhecer-se como indivíduo, caso não faça mais parte da organização, ou do grupo a que estava vinculado. Essa é uma consequiência facilmente visualizada, quando funcionários antigos são demitidos ou se aposentam após anos de dedicação à empresa.

Segundo Brickson (2000), cada uma das orientações de identidade pode ser impulsionada por elementos do contexto organizacional, tais como a estrutura organizacional, que se refere ao grau e à forma de integração entre os membros da organização, se eles estão primariamente atomizados como indivíduos, integrados por meio de redes que ultrapassam as fronteiras das divisões formais, ou separados por divisões e grupos formais. Outro elemento é a estrutura das tarefas executadas pelos indivíduos, ou seja, a maneira pela qual o trabalho é organizado, se de modo individual, por cooperação interpessoal ou em equipe. E ainda, a estrutura de reconhecimento, que demonstra como o desempenho é medido e recompensado, se de modo individual, pela cooperação interpessoal ou por equipe.

Dessa forma, é fácil perceber que ao valorizar o trabalho em equipe, a cooperação, participação nos lucros e resultados do grupo, entre outros, o que a maioria das empresas está buscando, é ativar uma identidade de orientação coletiva, em que os funcionários se reconhecem primeiramente como membros da organização em que trabalham, priorizando os objetivos da empresa em detrimento dos seus próprios objetivos.

\section{Possíveis Conseqüências do Processo de Construção das IDENTIDADES DOS INDIVÍDUOS NAS ORGANIZAÇÕES}

A análise feita aqui procura demonstrar que o processo de construção das identidades dos indivíduos pode ser visto de duas formas, como fonte de motivação e identificação dos funcionários em relação à empresa, o que é positivo para 
ambos, mas também como forma de moldar o comportamento das pessoas que trabalham na organização, o que pode trazer conseqüências negativas tanto para a empresa, como já foi comentado anteriormente, quanto para os indivíduos, como veremos a seguir.

Schirato (2000) desenvolveu uma pesquisa com ex-funcionários da Embraer, em que verificou, entre outras coisas, o impacto da demissão, e a conseqüente perda de identidade que essas pessoas demonstraram nos seus relatos. Segundo esta autora, as organizações estão exigindo mais do que adesão aos princípios e valores da empresa, o que está sendo cada vez mais solicitado é a entrega total ao mundo organizacional, onde, a partir de então, se estará total e absolutamente envolvido.

No discurso de inclusão do candidato ao quadro efetivo da organização, já está embutido o discurso de exclusão: se não houver identificação entre ambos com os valores e comportamentos, o desligamento será consequiência natural e, claro, por iniciativa do futuro colaborador, que não colaborou na proporção desejada. Os candidatos já são informados de que não fará parte da organização quem não se identificar integralmente com a história e com o comportamento da empresa. A adesão é mais do que aceitação: é superposição ao já constituído anteriormente, é o alinhamento do comportamento ao padrão de comportamento observado nos companheiros.

Schirato (2000, p. 100) ressalta ainda que:

na necessidade de sobrevivência dentro de um sistema desconhecido, e por isso hostil, é comum observarmos reações padronizadas, sem características pessoais, sem a impressão pessoal do indivíduo dentro do grupo. Ele passa a ser a extensão do comportamento do grupo na forma de vestir-se, de comer, de arrumar seu objetos, de organizar sua agenda, desenvolvendo uma "personalidade organizacional" que se sobrepõe à sua, quando não a substitui por inteiro.

Essa fusão de identidades - o eu organizacional e o eu individual do empregado - pode vir a resultar na perda da cidadania civil para uma suposta cidadania empresarial. Rompendo seus vínculos pessoais com o mundo fora da organização, o indivíduo deixa de sentir-se cidadão no sentido pleno do termo. Compartilhando dessa visão, podemos afirmar que a empresa não apenas emprega, e remunera a força de trabalho, ela praticamente ocupa todo o espaço afetivo, intelectual, e imaginário do indivíduo. É por meio da organização em que trabalham e do que ela lhes proporciona que as pessoas projetam seus sonhos e buscam alcançá-los.

Percebe-se com nitidez nesse estudo que a identificação com a organização muitas vezes acaba tornando-se uma obrigação dos funcionários. Assim, a maioria 
das pessoas não questiona o que faz no dia-a-dia das empresas, adotando tão cegamente certos comportamentos que, quando surge a necessidade de mudança, se sentem vulneráveis, resistindo fortemente, por acreditarem que as mudanças irão interferir no domínio que possuem do trabalho que realizam. Isso dificulta muito o processo de reconstrução das identidades dos indivíduos, cada vez mais necessário em ambientes de mudanças constantes.

\section{Mudança Organizacional e a Reconstrução das Identidades DOS INDIVÍDUOS ENVOLVIDOS}

Cada vez mais as empresas se preocupam com as mudanças que, mais do que nunca, se tornam universais. Grouard e Meston (2001) comentam que há atualmente constantes discussões sobre reestruturação, reorganização, implantação de novas tecnologias e novos métodos de distribuição, reorientação, reengenharia, fusões e aquisições, entre outras mudanças nas maneiras de pensar e agir.

É inegável que as mudanças estão cada vez mais presentes na vida das pessoas, tanto no âmbito organizacional como fora dele. Os motivos que levam a essas mudanças são os mais variados. Wood, Curado e Campos (1995) definem como sendo os objetivos mais freqüentes das mudanças nas organizações: melhorar a qualidade, aumentar a produtividade, refletir os valores dos novos líderes, reduzir custos e administrar conflitos.

De modo geral, podemos perceber que, quanto mais estável for a organização, mais difícil será a realização de mudanças, uma vez que as pessoas tendem a se acomodar, quando estão bem adaptadas à vida organizacional. Nesse sentido, a perfeita adaptação a determinado ambiente pode repentinamente transformar-se em grande obstáculo à mudança. Grouard e Meston (2001) ressaltam que o índice e a freqüência das mudanças podem ser diferentes, assim como as forças que as motivam, mas uma coisa é certa: as organizações devem mudar; e seja qual for a mudança, necessitará da desestabilização do estado existente.

Quando ocorrer de forma proativa e incremental, ou seja, progressivamente, o tempo para implementar a mudança será maior, e as pessoas terão mais condição de assimilar os motivos que levaram à necessidade de mudar. Já quando a sobrevivência da organização depende da mudança, aí podemos falar em mudança revolucionária, em que as pessoas são forçadas a mudar e não há tempo para assimilarem e se adaptarem às novas exigências. 
Vários autores consideram que, em geral, o tempo necessário para operar mudanças organizacionais é subestimado, por não se levar em conta os laços das pessoas com os elementos culturais. Para Motta e Vasconcelos (2002), mudar convicções e valores adquiridos com a experiência não é tarefa simples. Bertero (1996) define o processo de mudança organizacional como longo e problemático, podendo até encontrar semelhanças com o processo de psicoterapia individual. Para este autor, promessas de bons resultados não podem ser feitas por profissionais corretos, uma vez que os resultados são sempre incertos e o tempo demandado é necessariamente longo.

Estudo desenvolvido por Dutra (1996) verificou que, para realizar uma mudança organizacional efetiva, é necessário muito mais do que mudar a estrutura da empresa. A mudança organizacional é fruto de uma série de aspectos interagentes, e muitas vezes envolve a necessidade de alterações nos rituais, símbolos e pressupostos, entre outros elementos que formam a cultura organizacional. Devemos considerar que mudar elementos da cultura não é tarefa fácil, pois afetam as crenças, percepções e emoções das pessoas envolvidas.

No entanto, quando pensamos em mudanças, devemos analisá-las como algo positivo, que trará melhorias para a organização, que estará atualizando-se para se manter competitiva e, assim, alcançar os resultados esperados. Uma cultura organizacional que priorize a comunicação, justificando por que certas ações são mais valorizadas que outras, se adaptará melhor às mudanças do que uma cultura em que a forma como as pessoas devem agir é imposta, sem explicações ou justificativas. A comunicação e a participação efetiva dos funcionários é de fundamental importância em situações de mudança. As pessoas precisam entender por que devem mudar para que haja menos resistência.

Para Hernandez e Caldas (2002) a resistência à mudança é vista como uma das principais barreiras na implementação de processos de mudança e inovação. É importante destacar que essa resistência muitas vezes se deve ao fato de que a mudança implica uma reconstrução das identidades dos indivíduos no ambiente de trabalho. No entanto, como as mudanças geralmente dizem respeito à estratégia da empresa e ao seu modo de funcionamento, aqueles elementos profundos da identidade dos indivíduos, que estão bastante incorporados e dificilmente se transformam, não devem ser vistos como fonte de resistência ao processo de mudança, pois as identidades dos indivíduos podem ser reconstruídas sem alterá-los.

O momento da mudança geralmente é caracterizado por uma indefinição quanto à própria identidade da organização, quesito básico para que as pessoas se situem 
e consigam direcionar esforços para objetivos predefinidos. No entanto Schein (1989) reforça que o processo evolucionário geralmente não muda alguns elementos identitários profundos da organização, aqueles princípios e conceitos que se encontram profundamente assimilados pelos seus membros.

As mudanças organizacionais mais complexas ocorrem, quando envolvem a razão de ser da organização. Giroux e Dumas (1997) observam que as fusões e aquisições de empresas representam um tipo de experiência de mudança que força os indivíduos a renunciarem ao seu passado e, então, a desconstruírem seus engajamentos precedentes em certa forma de trabalhar, em certo estilo de relações sociais ou de práticas culturais. Esse tipo de mudança exige das pessoas mais do que a aprendizagem de novos modos de fazer (novos métodos e equipamentos) e novas formas de ligação (nova estrutura, nova cultura).

Segundo Hogg e Terry (2000), uma fusão ou aquisição é um caso especial de alteração da dinâmica das relações intragrupos e intergrupos nas organizações. Nesses casos, a resistência tende a ser maior, pois se torna necessário mudar os elementos identitários mais profundos e já completamente incorporados pelos membros da organização.Para Barros e Rodrigues (2001), quando uma empresa é adquirida por outra, o sentimento de inferioridade da primeira gera tensão e descontentamento, ampliados pelo temor de perda de sua cultura genuína. Esse medo de perder a identidade acaba gerando, na maioria das vezes, uma posição defensiva e, conseqüentemente, maior resistência à integração cultural.

No processo de reconstrução das identidades dos indivíduos, é de grande importância o papel da comunicação, no sentido de informar os empregados acerca dos valores declarados, as diretrizes, os objetivos e as definições gerais estabelecidas pela organização, incluindo o perfil que ela deseja para os seus empregados no novo contexto. É justamente a comunicação o meio privilegiado pelo qual se reconstrói, ao longo do tempo, a nova coletividade organizacional. Acreditamos que o engajamento das pessoas envolvidas no processo de mudança será maior, se forem levados em consideração por parte dos gestores, entre outras coisas, os sentimentos, dúvidas, inseguranças, opiniões e percepções dos indivíduos envolvidos.

\section{Conclusão}

Quando queremos conhecer a identidade de alguém, e para isso pedimos que 
a pessoa se identifique, é muito comum ouvirmos como resposta o nome da pessoa e a empresa na qual trabalha. A identidade vista como um fenômeno social é constituída pelos diversos grupos de que fazemos parte, por meio das relações que estabelecem seus membros entre si e com o ambiente onde vivem. Quando, ao nos identificarmos, destacamos a organização em que trabalhamos, podemos perceber que essa é mais significativa na construção da nossa identidade do que outros grupos relativos à nossa idade, etnia, ou estado civil, por exemplo.

A noção de identidade nas organizações se dá em função do relacionamento com outros, que é construído, mantido e modificado pelas características do contexto interativo organizacional. Ao compartilhar objetivos, regras, valores, entre outros, os indivíduos assumem comportamentos grupais moldados pela organização, motivados pela redução da incerteza de como devem sentir, agir, pensar, e ainda, de como serão vistos pelos outros. A função do grupo é definir papéis e, conseqüentemente, a identidade social dos indivíduos. Assim, a identidade passa a ser entendida como o próprio processo de identificação.

Esse processo de construção das identidades dos indivíduos nas organizações acontece geralmente de maneira natural, iniciando-se no momento de inserção na empresa, onde são dadas as diretrizes que devem ser seguidas, e são informados de quais comportamentos são adequados. Ao longo do tempo, as pessoas passam a incorporar determinadas maneiras de pensar e agir, ativando uma identidade de orientação coletiva, que tende a ser preservada. Assim, quando a empresa se vê em situações que exigem mudanças de comportamento, cada vez mais necessárias para se adequar às expectativas do mercado, a resistência é uma conseqüência natural, afetando as identidades dos indivíduos, que deverão ser reconstruídas.

A análise feita nos levou a perceber que, ao seguir os padrões sem questionamentos ou sugestões, os indivíduos podem vir a não distinguir mais sua identidade pessoal, ocorrendo uma despersonalização desses. No entanto, a partir do momento em que os indivíduos estão conscientes dos objetivos que se pretende atingir, e se identificam com eles, as organizações podem e devem estimular a flexibilidade de ação e criatividade desses, explicando as regras, pedindo sugestões, e motivando seus funcionários a participar ativamente da vida organizacional, sem perder produtividade e aumentando a satisfação. Além de evitar que os funcionários fiquem alienados, facilitará a implementação de mudanças, quando necessário.

Artigo recebido em 31.01.2004. Aprovado em 22.09.2004. 


\section{Referências Bibliográficas}

Ashforth, B. E., \&

Mael, E. (1989, January).

Social identity theory and the organization. Academy of Management Review, 14(1), 20-39.

Barros, B. T., \&

Rodrigues, S. B. (2001).

Compreendendo a dimensão cultural. In: Barros, B. T. (Org.). Fusões, aquisições \& parcerias (Cap. 5). São Paulo: Atlas.

Barros, B. T. (2001).

Encontro das culturas organizacionais. In: Barros, B.T. (Org.) Fusões, aquisições \& parcerias (Cap. 6). São Paulo: Atlas.

Berger, P., \&

Luckmann, T. (1983).

A construção social da realidade: tratado de sociologia do conhecimento (5th ed.). Petrópolis: Vozes.

Bertero, C. O. (1996).

Cultura organizacional e instrumentalização do poder. In: M. T. Fleury, \& R. M. Fischer. Cultura e poder nas organizações (2a ed.). São Paulo: Atlas.

\section{Brickson, S. (2000).}

The impact of identity orientation on individual and organizational outcomes in demographically diverse settings. Academyof Management Review, 25(1), 82-101.
Dupuis, J. (1996).

Antropologia, cultura e organização: proposta de um modelo construtivista. In: J. Chanlat, (Coord.). $O$ indivíduo na organização: dimensões esquecidas (Vol. 3, pp. 231-251). São Paulo: Atlas.

Dutra, J. S. (1996).

A utopia da mudança das relações de poder na gestão de recursos humanos. In: M. T. Fleury, \& R. M. Fischer (Coords.). Cultura e poder nas organizações (2a ed.). São Paulo: Atlas.

Freitas, M. E. (1991).

Cultura organizacional: formação, tipologias, e impacto. São Paulo: MakronBooks.

Gioia, D. A.,

Schultz, M., \&

Corley, K. G. (2000, January).

Organizational identity, image, and adaptative instability. Academy of Management Review, 25(1), 63-81.

Giroux, N., \&

Dumas, D. (1997).

Trois modalités d'intégration des fusions/acquisitions: l'intégration planifiée, l'intégration émergente et l'intégration conjointe. Actes du Congrès de l'Association internationale de management stratégique, HEC, Montreal, 6, 1-23.

Grouard, B., \&

Meston, F. (2001).

Empresa em movimento. São Paulo:

Negócio Editora. 
Hernandez, J. M. C., \&

Caldas, M. P. (2002).

Resistência à mudança. In: T. Wood, Jr. (Coord.). Gestão empresarial: o fator humano (Cap. 4, pp.71-97). São Paulo: Atlas.

Hogg, M. A., \&

Terry, D. J. (2000, January).

Social identity and self-categorization processes in organizational contexts. Academy of Management Review, 25, pp. 121-140.

Lopes, L. P. M. (2001).

Práticas narrativas como espaço de construção das identidades sociais: uma abordagem socioconstrucionista. Narrativa, identidade e clínica (pp. 56-71). Rio de Janeiro: Edições IPUB/ CUCA.

Motta, F. C. P., \&

Vasconcelos, I. G. (2002).

Teoria geral da administração. São Paulo: Pioneira Thomson Learning.

Oliveira, M. C. L., \&

Bastos, L. C. (2001).

Saúde, doença e burocracia: pessoas e dramas no atendimento de um seguro saúde. In: B. T., Ribeiro, C. C., Lima, \& M. T. L., Dantas, (Orgs.). Narrativa, identidade e clínica (pp. 162-187). Rio de Janeiro: Edições IPUB/CUCA.

Schein, E. (1989).

Organizational culture and leadership (2th ed.). San Francisco: Jossey Bass.
Schein, E. (2001).

Guia de sobrevivência da cultura coorporativa. (2th ed). Rio de Janeiro: José Olympio.

Schirato, M. A. R. (2000). O feitiço das organizações: sistemas imaginários. São Paulo: Atlas.

Silva, J. R. G., \&

Vergara, S. C. (2002).

Mudança organizacional e as múltiplas relações que afetam a reconstrução das identidades dos indivíduos. Anais do Encontro Nacional dos Programas de PósGraduação em Administração, Salvador/BA, 26.

Silva, J. R. G., \&

Vergara, S. C. (2000).

O significado da mudança: as percepções dos funcionários de uma empresa brasileira diante da expectativa de privatização. Revista de Administração Pública, 34(1), 7999.

Taylor, D. M., \&

Moghaddam, M. (Orgs.). (1987).

Theories of intergroup relations: international social psychological perspectives. New York: Praeger.

Ting-Toomey, S. (1998).

Communicating across cultures. New York: The Guilford Press.

Turner, J.C. (1982).

Towards a cognitive redefinition of the social group. In: H. Tajfel (Ed.). Social identity and intergroup relations. Cambridge: Cambridge University Press 
Wood, T., Jr.,

Curado, I. B., \&

Campos, H. M. (1995).

Vencendo a crise: mudança organizacional na Rhodia Farma. In: T. Wood, Jr. (Coord). Mudança organizacional: aprofundando temas atuais em administração de empresas (Cap. 10, pp. 188-216). São Paulo: Atlas.
Zanelli, J. C. (no prelo).

Interação humana e gestão: uma compreensão introdutória da construção organizacional. Rio de Janeiro: Editora LAB. 